\title{
Predicting Healthy Eating Intentions in Saudi Adults
}

\author{
Hala Hazam Al Otaibi \\ Department of Food Sciences and Nutrition, Community Nutrition, College of Agriculture and Food Sciences, King Faisal \\ University, Al-Ahsa, KSA \\ Email: hhalotaibi@kfu.edu.sa,halaalotaibi5m@gmail.com
}

How to cite this paper: Al Otaibi, H.H. (2018) Predicting Healthy Eating Intentions in Saudi Adults. Food and Nutrition Sciences, 9, 1358-1367.

https://doi.org/10.4236/fns.2018.912097

Received: November 14, 2018

Accepted: December 11, 2018

Published: December 14, 2018

Copyright $\odot 2018$ by authors and Scientific Research Publishing Inc. This work is licensed under the Creative Commons Attribution International License (CC BY 4.0).

http://creativecommons.org/licenses/by/4.0/

\begin{abstract}
Background: Despite the dietary guidelines for healthy eating (HE) and daily recommended food servings to promote healthy dietary patterns among the population in Saudi Arabia, the incidence of unhealthy eating has increased. Methods: We used the Theory of Planned Behavior (TPB) as a conceptual framework to explain and understand important factors affecting HE among Saudi adults. Six hundred forty-seven Saudi adults were recruited for an online survey. Results: The mean age of the subjects was $26.74 \pm 8.21$ years; the majority of subjects $(74.1 \%)$ were young adults and were primarily female $(60.1 \%)$. The correlation analysis indicated a positive correlation between all the TPB components and HE. The present study shows that positive attitudes and perceived behavioral control are the strongest predictors of HE intuition. The path analysis showed a good overall model fit (RMSEA $=0.034$; $\mathrm{CFI}=$ 0.975; NFI $=974$; GFI $=0.975)\left(\chi^{2}=4.1964, \mathrm{df}=3, \mathrm{p}=0.45\right)$. Conclusion: Understanding the factors that influence behavior can improve dietary patterns and quality of life and can reduce the risks of chronic diseases.
\end{abstract}

\section{Keywords}

Path Analysis, Healthy Eating, Saudi, Adults

\section{Introduction}

In Saudi Arabia (SA), similar to other Gulf Cooperation Council (GCC) countries, the nutrition transition has contributed to the rising burden of chronic diseases (obesity, diabetes, cardiovascular diseases, cancers) [1]. The Saudi Health Interview Survey [2] found that the prevalence of obesity among Saudis is $28.7 \%$, which is attributed to unhealthy dietary habits, such as high intake of 
sugar, meat, fat and low intake of fruits and vegetables. Healthy eating is an important determinant of many health outcomes. The Ministry of Health [3] published eight easily understandable dietary guidelines for healthy eating and daily recommended food servings according to age groups to promote healthy dietary patterns among the population.

Despite the improvement in healthy eating among Saudi adults, the incidence of unhealthy eating has also increased [4]. In countries such as Saudi Arabia with a wide range of food and beverages, individuals are faced with difficulties in meeting their daily nutritional requirements without excessive caloric intake. A number of studies have investigated implementing dietary guidelines and adopting healthy eating among Saudi adults, and these studies described the amount of consumption of different types of food groups and found that a small percentage of the Saudi population met the dietary recommendations [4] [5] [6] [7]. However, behavioral change is not easily achieved; educational interventions based on theory to effectively help people increase healthy eating adherence are clearly needed.

The Theory of Planned Behavior (TPB) is widely applied to understand behavioral decision-making and is commonly used to predict engagement in specific behaviors [8]. According to the TPB, if individuals have positive attitudes, subjective norms, and high perceived behavioral control, they are more likely to intend to engage in healthy eating behavior (less fat, sugar, and meat intake and more fruit, vegetable, whole grains, and milk intake), which in turn will predict healthy eating behaviors [9] [10]. Similarly, Ajzen and Albarracin [11] found that the TPB predicted healthy eating intentions.

To our knowledge, no previous studies have used the TPB as a conceptual framework to explain and understand important factors affecting healthy eating among Saudi adults. We tested the usefulness of the TPB as a framework to understand the role of psychological factors (attitudes, subjective norms, perceived behavioral control, and intuition) in influencing healthy eating behavior. Understanding these psychological factors is a necessary step to design effective educational interventions to increase healthy eating intake among the population.

\section{Materials and Methods}

A community sample without chronic illness was selected as a target group. Six hundred forty-seven Saudi adults responded to recruitment attempts for an online survey (Google Docs). To avoid missing data, the settings were such that no respondent could return an incomplete questionnaire. The authors distributed the online questionnaire to friends, and colleagues via email and WhatsApp, and we asked them to forward it to their friends, colleagues or anyone interested in contributing to the study.

The questionnaire included three parts. The first part related to socio-demographic variables, such as age, sex, level of education, work status, and 
household income. In this part, we asked subjects to record their weight and height. The second part consisted of healthy eating (HE) behavior, which is based on the Saudi daily recommended food serving according to age groups for males and females (aged 19 - 50) (MHO, 2012). Four questions about the average daily intake from food groups ("Do you consume 7 - 8 servings of fruits and vegetables daily?"; "Do you consume six servings of cereal and bread daily?"; "Do you consume two servings of milk and dairy products daily?"; "Do you consume two servings of meat and meat substitutes daily?"), with responses on a 7-point Likert scale ( $1=$ never to $7=$ every day).

In the third part, we used the TPB components reflecting healthy dietary behaviors previously developed and used by Armitage and Connor [12], Astrom and Rise [13], and Louis et al. [14]. All the items were translated from English to Arabic and pre-tested for clarity of meaning, then translated back to ensure validity.

\subsection{Intentions (INT)}

This section included three items (for example, "I intend to eat a healthy diet over the next week.") with responses on a 7-point Likert scale ( $1=$ strongly disagree to $7=$ strongly agree); higher scores indicated greater intentions to eat a healthy diet. The reliability of the items was $\alpha=0.81$, which was deemed acceptable.

\subsection{Attitudes (ATT)}

This section included one item that measured healthy diet attitudes ("I think eating a healthy diet in the next week is ...") with responses on a 7-point Likert scale with -3 as extremely un-enjoyable to +3 as extremely enjoyable. Higher scores reflected positive attitudes toward healthy eating. The Cronbach's alpha was 0.77 .

\subsection{Perceived Behavioral Control (BC)}

This section included seven items, such as "I believe I have the ability to eat a healthy diet in the next week." with responses on a 7-point Likert scale. Higher scores indicated more agreement, certainty and ability. The Cronbach's alpha was 0.78 .

\subsection{Subjective Norms (SN)}

This section included three items as follows: "People who are important to me think I ' $1=$ should not eat a healthy diet to $7=$ should eat a healthy diet"'; "People who are important to me would ' $1=$ disapprove of my eating a healthy diet to 7 = approve of my eating a healthy diet"; and "People who are important to me want me to eat a healthy diet". Responses were on a 7-point Likert scale $(1=$ strongly disagree to $7=$ strongly agree). The Cronbach's alpha was 0.79 .

\section{Data Analysis}

The data were analyzed using SPSS version 23. Body mass index (BMI) was cal- 
culated and categorized according to World Health Organization guidelines (1998) [15]. Descriptive statistics, including means, standard deviations, frequencies, and percentages, were used. Pearson Correlation analysis used to determine the relationships among healthy eating behavior and the TPB components. Path analysis was conducted using AMOS (Analysis of Moment Structures, version 23) to examine the association between intentions for healthy eating behavior and the ТРВ components. Figure 1 represents the structural model with a standardized solution. The model consisted of INT for HE behavior as a latent dependent variable (endogenous variable) influenced by three (ATT, BC, and SN) latent independent variables (exogenous variables). To assess the overall model fit, chi-squared $\left(\chi^{2}\right)$, Root Mean Square Error of Approximation (RMSEA), Goodness of Fit Index (GFI), comparative fit index (CFI), and Normed Fit Index (NFI) were examined. Values greater than 0.90 in CFI, NFI and GFI were acceptable (Bentler, 1990) [16]. Values lower than 0.08 in RMSEA generally reflected a good model fit (Hu and Bentler, 1999) [17], and not significant values of $\chi^{2}$ indicated that the model fits the data well (Iacobucci, 2010) [18].

\section{Results}

The ages of the subjects ranged from 18 to 49 years $(26.74 \pm 8.21)$, and the majority $(74.1 \%)$ of the subjects were young adults (18 - 30 years). Subjects were primarily female $(60.1 \%)$, half of them reported being married, $40.7 \%$ of the subjects worked full-time, and $51.7 \%$ of them had a monthly income of more than five thousand Saudi Riyals. The mean BMI was $25.27 \pm 8.71$, which is slightly overweight, while half of the subjects were a normal weight, and 70 (10.9\%) were underweight (Table 1). The results from the correlation analysis indicated a positive correlation between all TPB components and HE (Table 2).

Figure 1 displays the path coefficients and shows a good overall model fit $(\mathrm{RMSEA}=0.034$; CFI $=0.975 ; \mathrm{NFI}=974 ; \mathrm{GFI}=0.975)\left(\chi^{2}=4.1964, \mathrm{df}=3, \mathrm{p}=\right.$ $0.45)$. The squared multiple correlations were significant for INT and HE $\left(\mathrm{R}^{2}=\right.$ 0.86 and 0.34 , respectively). There was significant covariance between ATT and $\mathrm{BC}$ (path estimate $=0.56, \mathrm{p}<0.000$ ) and between $\mathrm{BC}$ and $\mathrm{SN}$ (path estimate $=$ $0.22, \mathrm{p}<0.000$ ); there was no significant covariance between ATT and SN (path estimate $=0.07, \mathrm{p}=0.067$ ). The ATT (path estimate $=0.83, \mathrm{p}<0.000)$ and BC (path estimate $=0.15, \mathrm{p}<0.000$ ) were significant. There were positive predictors

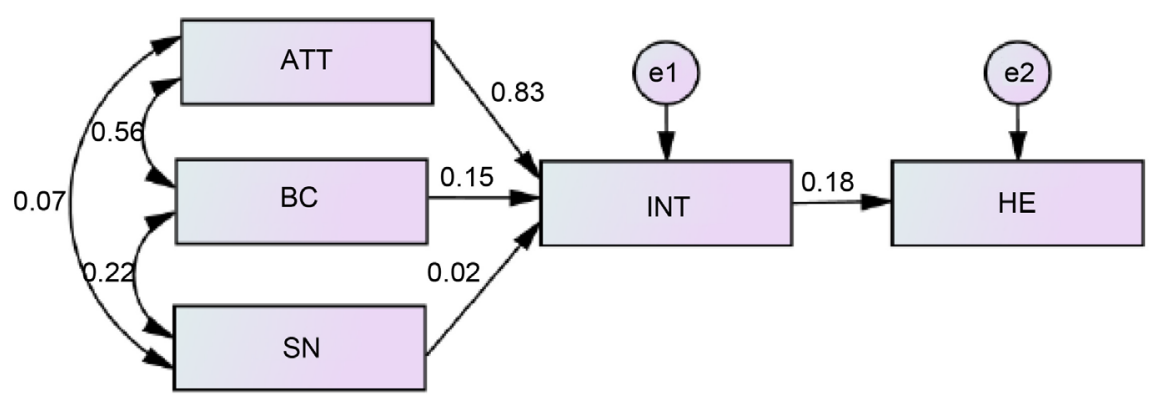

Figure 1. Path model with standardized regression coefficients. 
Table 1. Characteristics of the study subjects $(\mathrm{N}=642)$.

\begin{tabular}{|c|c|}
\hline Variables & Number $\%$ \\
\hline Age (mean $\pm S D)$ years. & $26.74 \pm 8.21$ \\
\hline 18 - 30 years. & $476(74.1 \%)$ \\
\hline 31 - 40 years. & $146(21.2 \%)$ \\
\hline 41 - 50 years. & $20(4.7 \%)$ \\
\hline \multicolumn{2}{|l|}{ Gender } \\
\hline Males. & $256(39.9 \%)$ \\
\hline Females. & $386(60.1 \%)$ \\
\hline \multicolumn{2}{|l|}{ Marital status } \\
\hline Un-married. & $323(50.3 \%)$ \\
\hline Married. & $319(49.7 \%)$ \\
\hline \multicolumn{2}{|l|}{ Education } \\
\hline Secondary or less. & $221(34.5 \%)$ \\
\hline College or higher & $421(65.5 \%)$ \\
\hline \multicolumn{2}{|l|}{ Work status } \\
\hline Employed. & $261(40.7 \%)$ \\
\hline Unemployed . & $381(59.3 \%)$ \\
\hline \multicolumn{2}{|l|}{ Household income (monthly in Saudi Riyals ) } \\
\hline$\leq 5000$ & $310(48.3 \%)$ \\
\hline$>5000$ & $332(51.7 \%)$ \\
\hline Body mass index $\left(\mathrm{kg} / \mathrm{m}^{2}\right)($ mean $\pm \mathrm{SD})$. & $25.27 \pm 8.71$ \\
\hline Underweight. & $70(10.9 \%)$ \\
\hline Normal weight. & $324(50.5 \%)$ \\
\hline Overweight. & $138(21.5 \%)$ \\
\hline Obese. & $110(17.1 \%)$ \\
\hline
\end{tabular}

Table 2. Correlation between healthy eating behavior and the TPB components.

\begin{tabular}{|c|c|c|c|c|c|c|}
\hline Variables & Mean \pm SD & 1 & 2 & 3 & 4 & 5 \\
\hline 1-Intentions & $12.28 \pm 1.97$ & 1 & & & & \\
\hline 2-Attitudes & $4.41+0.69$ & $0.549^{* *}$ & 1 & & & \\
\hline $\begin{array}{l}\text { 3-Perceived behavioral } \\
\text { control }\end{array}$ & $29.36 \pm 4.03$ & $0.617^{* *}$ & $0.604^{* *}$ & 1 & & \\
\hline 4-Subjective norms & $9.51+1.41$ & $0.113^{* *}$ & $0.102^{* *}$ & $0.121^{\star *}$ & 1 & \\
\hline $\begin{array}{l}\text { 5-healthy eating behavior } \\
\qquad{ }^{*} \mathrm{P} \leq 0.01\end{array}$ & $11.39+2.72$ & $0.116^{* *}$ & $0.351^{* *}$ & $0.544^{* *}$ & $0.136^{\star *}$ & 1 \\
\hline
\end{tabular}

of INT to HE, and the latter was the strongest predictor of INT (path estimate = $0.18, \mathrm{p}<0.000$ ). The $\mathrm{SN}$ (path estimate $=0.02, \mathrm{p}=0.203$ ) was not a significant predictor of INT or HE. 


\section{Discussion}

This study used the TPB to investigate the role of ATT, BC, and SN in influencing HE among Saudi adults. The results showed that almost all TBP variables satisfactorily predicted HE INT behaviors among Saudi adults. The findings also indicated that positive ATT was the most important predictor of behavioral INT and HE behaviors and of the beliefs of our subject about the possible attributes of performing HE behavior. Similarly, Psouni et al. [19] found ATT significant predictors of HE intentions among 361 adults from Greece, especially among normal weight subjects. Staunton et al. [20] found that ATT was positively associated with HE INT; 119 students from an Australian university held favorable ATT, which inferred that their family and friends approved of eating healthily, and they reported higher INT to eat healthily. In contrast, ATT had a moderate impact on the INT to fruit and vegetable intake [21].

$\mathrm{BC}$ was defined as the control one believes he or she has over performing a behavior proposed to predict behavior directly, as well as indirectly via INT, to the extent that perceptions of control reflect the actual presence or absence of barriers that facilitate or inhibit individuals' ability to act on their INT [22]. Our study showed that BC accounted for moderation in the prediction of HE INT compared with ATT; an explanation of our finding is that the majority of our subjects $(74.1 \%)$ are young adults (18 - 30 years) who usually have lower self-control of HE [23]. In contrast, McDermott et al. [24] found BC had stronger associations with INT in older adults compared to younger adults. Another study by Quintiliani et al. [25] suggested that BC is significantly associated with healthy dietary behavior among public housing residents in the United States. Staunton et al. [20] found that greater BC did not predict HE behavior.

$\mathrm{SN}$ is defined as social pressure to engage in or not to engage in a specific behavior [22]. We found that SN was not a predictor of behavioral INT and HE behaviors. Consistent with our results, Psouni et al. [19] found SN was not a significant predictor of HE INT; however, Conner et al. [26] showed that INT to eat healthily was predicted by ATT, BC and SN. The possible explanations for this result could be found in the instruments we used to recommended referent for the TPB is (“... people who are important to me ...") as interpersonal norms may be less salient and comparatively weaker in our subjects, or it might be that there is a lack of association between subjective norm and intentions [27].

Behavior INT is determined by an individual's ATT and BC toward the behavior and SN perception of that behavior [28]. All TPB constructs explained 86\% of the variance of HE INT, which is similar to Hagger et al., [29] who found that all TPB constructs explained healthy dietary behaviors $67.85 \%$ in meta-analytic path analyses of the theory in two behavioral contexts, alcohol and dietary behaviors. Lower variance was reported by Carfora et al., [21] in which all TPB constructs explained $49 \%$ of the variance of intention of fruit and vegetable intake; however, they found lower percentages and studied only fruits and vegetables. 


\section{Strengths and Limitations}

We made efforts to recruit a large community sample primarily composed of subjects with a college education or higher. Males were well represented (40\%), which is important because they are usually under-represented in research concerning HE behavior. The findings showed that the TPB is a useful framework for understanding HE behaviors among Saudi adults. Despite these strengths, this study has a number of limitations. First, a cross-sectional study design cannot clearly reveal the cause-and-effect relationships between the variables and was performed at a single point time, which limited the possibility of varied findings.

Second, the online survey method may lead to slightly biased sampling as it represents individuals who are already interested in the topic; completers or dropouts in online surveys might differ in educational status and sex, and men are usually more likely to quit participation early [30]. Additionally, a predominance of young users in online surveys was observed as the majority of our subjects are between 18 and 30 years of age of age. Third, the assessment of the daily intake of food groups, height and weight were based on self-reported responses and might not give reliable and accurate daily food group intakes and BMI scores (due to overestimation or underestimation). Finally, our sample was not representative of the general population.

\section{Conclusions and Recommendations}

To our knowledge, this is the first study to apply the TPB to predict HE INT among Saudi adults. The present study shows that positive ATT and BC are the strongest predictors of HE INT. A total of $86 \%$ of the variance in HE INT scores was explained by the Path analysis model. Findings from this study may help in the development of more effective intervention strategies for increasing HE INT among Saudi adults. Future studies investigating dietary behavior might consider studying each food group separately. This approach may give us more consequential data regarding the predictors of adherence to each food group recommendations, and intervention studies can target and encourage intake of the different food groups.

Further research is required to identify psychosocial (e.g., self-efficacy, self-identity) and other modifiable factors (e.g., food purchase and consumption environments) not considered in the TPB framework, which may better explain adherence to dietary recommendations. Understanding the factors that influence behavior and therefore facilitate the prediction and understanding of HE can improve the quality of life and reduce the risks of chronic diseases.

\section{Conflicts of Interest}

The author declares no conflicts of interest regarding the publication of this paper. 


\section{References}

[1] Afshin, A., Micha, R., Khatibzadeh, S., Fahimi, S., Shi, P., Powles, J., Singh, G., Yakoob, M.Y., Abdollahi, M. and Al-Hooti, S. (2015) The Impact of Dietary Habits and Metabolic Risk Factors on Cardiovascular and Diabetes Mortality in Countries of the Middle East and North Africa in 2010: A Comparative Risk Assessment Analysis. BMJ Open, 5, e006385. https://doi.org/10.1136/bmjopen-2014-006385

[2] Saudi Ministry of Health (2013) Survey of Health Information. http://www.moh.gov.sa/en/ministry/statistics/pages/healthinformatics.aspx

[3] General Director of Nutrition, Ministry of Health (2012) Saudi Dietary Guideline (Healthy Diet Palm). Ministry of Health Publications, Riyadh.

[4] Moradi-Lakeh, M., El-Bcheraoui, C., Afshin, A., Daoud, F., Al-Mazroa, M.A., Al-Saeedi, M., Mohammed Basulaiman, M., Memish, Z.A., Abdullah, A., Al Rabeeah, A.A. and Mokdad, A.H. (2017) Diet in Saudi Arabia: Findings from a Nationally Representative Survey. Public Health Nutrition, 20, 1075-1081. https://doi.org/10.1017/S1368980016003141

[5] El Bcheraoui, C., Tuffaha, M., Daoud, F., Kravitz, H., Al Mazroa, M.A., Al Saeedi, M., Memish, Z.A., Basulaiman, M., Al Rabeeah, A.A. and Mokdad, A.H. (2016) On Your Mark, Get Set Go: Levels of Physical Activity in the Kingdom of Saudi Arabia, 2013. Journal of Physical Activity \& Health, 13, 231-238. https://doi.org/10.1123/jpah.2014-0601

[6] Alsufiani, H.M., Kumosani, T.A., Ford, D. and Mathers, J.C. (2015) Dietary Patterns, Nutrient Intakes, and Nutrional and Phusical Activity Status of Saudi Older Adults: A Narrative Review. Journal of Aging Research \& Clinical Practice, 4, 2-11.

[7] El Bcheraoui, C., Basulaiman, M., AlMazroa, M., Tuffaha, M., Daoud, F., Wilson, S., Al Saeedi, M., Alanazi, F., Ibrahim, M., Ahmed, E., Hussain, S., Salloum, R.M., Abid, O., Al-Dossary, M., Memish, Z., Al Rabeeah, A. and Mokdad, A. (2015) Fruit and Vegetable Consumption among Adults in Saudi Arabia, 2013. Nutrition and Dietary Supplements, 7, 41-49.

[8] Ajzen, I. (1991) The Theory of Planned Behavior. Organizational Behavior and Human Decision Processes, 50, 179-211. https://doi.org/10.1016/0749-5978(91)90020-T

[9] Gronhoj, A., Bech-Larson, T., Chan, K. and Tsang, L. (2013) Using Theory of Planned Behavior to Predict Healthy Eating among Danish Adolescents. Health Education, 113, 4-17. https://doi.org/10.1108/09654281311293600

[10] Bassett-Gunter, R.L., Levy-Milne, R., Naylor, P.J., Downs, D.S., Benoit, C., Warburton, D.E.R., Blanchard, C.E. and Rhodes, R.E. (2013) Oh Baby! Motivation for Healthy Eating during Parenthood Transition: A Longitudinal Examination with a Theory of Planned Behavior Perspective. Journal of Behavioral Nutrition and Physical Activity, 10, 88. https://doi.org/10.1186/1479-5868-10-88

[11] Ajzen, I. and Albarracin, D. (2007) Predicting and Changing Behavior: A Reasoned Action Approach. In: Fishbein, M., Ajzen, I., Albarracin, D. and Hornik, R., Eds., Prediction and Change of Health Behavior. Applying the Reasoned Action Approach, Lawrence Erlbaum, Mahwah, NJ, 3-22.

[12] Armitage, C.J. and Connor, M. (2001) Efficacy of the Theory of Planned Behavior: A Meta-Analytic Review. British Journal of Social Psychology, 40, 471-499. https://doi.org/10.1348/014466601164939

[13] Astrom, A.N. and Rise, J. (2001) Young Adults' Intentions to Eat Healthy Good: Extending the Theory of Planned Behavior. Psychology and Health, 16, 223-237. 
https://doi.org/10.1080/08870440108405501

[14] Louis, W.R., Chan, M.K.H. and Greenbaum, S. (2009) Stress and the Theory of Planned Behavior. Understanding Healthy and Unhealthy Eating Intentions. Journal of Applied Social Psychology, 39, 472-493. https://doi.org/10.1016/j.jcps.2009.09.003

[15] World Health Organization (1998) Obesity: Preventing and Managing the Global Epidemic. Report of a World Health Organization Consultation on Obesity. WHO, Geneva.

[16] Bentler, P.M. (1990) Comparative Fit Indexes in Structural Models. Psychological Bulletin, 107, 238-246. https://doi.org/10.1037/0033-2909.107.2.238

[17] Hu, L. and Bentler, P.M. (1999) Cutoff Criteria for Fit Indexes in Covariance Structure Analysis: Conventional Criteria versus New Alternatives. Structural Equation Modeling, 6, 1-55. https://doi.org/10.1080/10705519909540118

[18] Iacobucci, D. (2010) Structural Equations Modeling: Fit Indices, Sample Size, and Advanced Topics. Journal of Consumer Psychology, 20, 90-98. https://doi.org/10.1016/j.jcps.2009.09.003

[19] Psouni, S., Hassandra, M. and Theodorakis, Y. (2016) Exercise and Healthy Eating Intentions and Behaviors among Normal Weight and Overweight/Obese Adults. Psychology, 7, 598-611. https://doi.org/10.4236/psych.2016.74062

[20] Staunton, M., Louis, W.R., Smith, J.R., Terry, D.J. and McDonald, R.I. (2014) How Negative Descriptive Norms for Healthy Eating Undermine the Effects of Positive Injunctive Norms. Journal of Applied Social Psychology, 44, 319-330. https://doi.org/10.1111/jasp.12223

[21] Carfora, V., Caso, D. and Conner, M. (2016) The Role of Self-Identity in Predicting Fruit and Vegetable Intake. Appetite, 106, 23-29.

https://doi.org/10.1016/j.appet.2015.12.020

[22] Montano, D.E. and Kasprzyk, D. (2008) Theory of Reasoned Action, Theory of Planned Behaviour, and the Integrated Behavioural Model. In: Glanz, K., Rimer B.K. and Viswanath, K., Eds., Health Behaviour and Health Education, Theory, Research and Practice, 4th Edition, John Wiley \& Sons, Jossey-Bass, San Francisco, 67-96.

[23] Kothe, E.J. and Mullan, B.A. (2014) Interaction Effects in the Theory of Planned Behavior: Predicting Fruit and Vegetable Consumption in Three Prospective Cohorts. British Journal of Health Psychology, 20, 549-562.

[24] McDermott, M.S., Oliver, M., Simnadis, T., Beck, E.J, Coltman, T., Iverson, D., Caputi, P. and Sharma, R. (2015) The Theory of Planned Behaviour and Dietary Patterns: A Systematic Review and Meta-Analysis. Preventive Medicine, 81, 150-156. https://doi.org/10.1016/j.ypmed.2015.08.020

[25] Quintiliani, L.M., DeBiasse, M.A., Branco, J.M., Bhosrekar, S.G., Rorie, J.A. and Bowen, D.J. (2014) Enhancing Physical and Social Environments to Reduce Obesity among Public Housing Residents: Rationale, Trial Design, and Baseline Data for the Healthy Families Study. Contemporary Clinical Trials, 39, 201-210. https://doi.org/10.1016/j.cct.2014.08.005

[26] Conner, M., Norman, P. and Bell, R. (2002) The Theory of Planned Behavior and Healthy Eating. Health Psychology, 21, 194-201.

https://doi.org/10.1037/0278-6133.21.2.194

[27] Rivis, A. and Sheeran, P. (2003) Descriptive Norms as an Additional Predictor in the Theory of Planned Behavior: A Meta-Analysis. Current Psychology Develop- 
mental, Learning, Personality, Social, 22, 218-233.

https://doi.org/10.1007/s12144-003-1018-2

[28] Glanz, K. and Rimer, B.K. (2005) Theory at a Glance: A Guide for Health Promotion Practice. US Dept. of Health and Human Services, Public Health Service, National Institutes of Health, National Cancer Institute.

http://www.sbccimplementationkits.org/demandrmnch/wp-content/uploads/2014/0 2/Theory-at-a-Glance-A-Guide-For-Health-Promotion-Practice.pdf

[29] Hagger, M.S., Chan, D.K.C., Protogerou, C. and Chatzisarantis, N.L.D. (2016) Using Meta-Analytic Path Analysis to Test Theoretical Predictions in Health Behavior: An Illustration Based on Meta-Analyses of the Theory of Planned Behavior. Preventive Medicine, 89, 154-161. https://doi.org/10.1016/j.ypmed.2016.05.020

[30] Ross, M.W., Daneback, K., Månsson, S.A., Tikkanen, R. and Cooper, A. (2003) Characteristics of Men and Women Who Complete or Exit from an On-Line Internet Sexuality Questionnaire: A Study of Instrument Dropout Biases. Journal of Sex Research, 40, 396e402. https://doi.org/10.1080/00224490209552205 